International Journal on Integrating Technology in Education (IJITE) Vol.8, No.1, March 2019

\title{
Use of TEChNOLOgY In Education, But at WHAT COST?
}

\author{
Avanti P. Sethi \& Ramesh Subramoniam \\ Jindal School of Management, University of Texas at Dallas, Texas, USA
}

\begin{abstract}
Use of technology in the field of education has been a blessing. Faster grading, quicker notes / media availability for students, interactive communication outside of classrooms with students and faculty, online courses etc. have added to the enhancement of our education system. But when technology is pushed in teaching without proper thought, it becomes a black box approach at the cost of intuition, commonsense, and overall understanding of the concepts. Instead of supplementing technology in the process of learning, it has been used in making the black box approach more common. When we can shift the question from "How to educate with technology?" to "How to teach people best, and how should we design learning experiences in light of existing technology?", then learning becomes a way to quench curiosity, and passion for learning will become a never ending pursuit for students. Models and textbook theories can help build the knowledge base, but they miss the context [5,7]. Students take them at face value without thinking through the real world implications. This is a recipe for failure since the industry expects business school students to tell the story with a strong reference to the context. A simplistic understanding of the formulas is what students' need instead of a plug and solve formula based teaching method.
\end{abstract}

\section{KEYWORDS}

MS Excel,Break-even Analysis, Probability Distribution, Lines and circles

\section{INTRODUCTION}

There was a time, not long ago, when we travelled all over the world by following "paper" maps. We learned how to brake cars during icy conditions to avoid skids. We scratched our heads or call 5 friends if we forgot who won Superbowl XIII.

There was a time teaching meant making and saving the precious order of transparencies. Multimedia presentation meant lots of video and audio tapes. We communicated with the students only during the class time or office hours.

We can go on and on, but the point is, our lives are no longer the same. Internet, cell phones, computers, artificial intelligence, medical science, etc. have changed us so much that we would feel utterly helpless if we went back just a few years. Researchers [6] found increased student independence using technology and found it easier to differentiate and provide corrective feedback, while helping students build fluency. Researchers [8] believed that the integration of technology into the learning environment of schools creates a student-centered, technology-based learning environment that allows the student to have greater control and responsibility of the learning process. As students take control of the learning process, the role of the teacher changes from knowledge provider to facilitator of learning.

The facilitation of the learning process is what we believe has become critically important more than ever for teachers as technology grips the business schools. This insight is a result of 57 years 
of combined experience of the authors of this article from industry, consulting and academic teaching in business schools. At the same time, the fundamentals haven't changed. We still need to eat healthy food as we did 50 years ago to keep healthy. We can use whichever exercise machine we want, but still have to huff and puff to remain fit. A similar logic can be applied to learning. After all, learning is a form of exercise and regardless of the tool, until we "sweat", we can't really process knowledge. There is no one-a-day pill that will make us a scientist or a doctor or a financial analyst. But, unfortunately, the trend in education has been in this.

As discussed in this article, there is a predominance of this one-a-day pill approach which is commonly known as a black-box approach. The availability of technology - in terms of modern calculators (read smart phones) and Excel - has made it so painless that the students don't even complain. A typical test scenario could be that the professor provides the formulas, the student uses a calculator, plugs-in the numbers, and writes the answer.

Here by giving very simple examples, some from popular textbooks, we show how learning, with the aid of constantly changing technology, has become a mechanical process.

\section{Cost-Volume Analysis}

Stevenson [1] in one of the widely used textbook in Operations Management provides and applies a set of 5 formulas for a simple break-even problem:

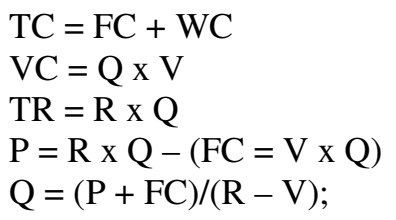

A student can plug-in the values of the Q's and V's etc. and get the solution. And a collection of such solution awards the student an A grade.

Now, if Fixed cost $=\$ 4,000$, Variable cost $=\$ 7$ and Selling price $=\$ 9$, then wouldn't the breakeven point simply be 2000 because we make a profit of $\$ 2$ / unit and we need to cover $\$ 4,000$ of Fixed cost? And if we want to make a profit of $\$ 5,000$, we have to make an additional 2,500 units which makes it a total of 4,500 units.

A student who understands the logic can solve any problem in any format, but taught with the blackbox approach as suggested by the above textbook will make him always uneasy and unsure. In fact, there is a better chance of a student solving this problem on his own if he is not actually taught because then he will use commonsense and reasoning to figure it out.

\section{Probability and Statistics}

A very important parameter in statistics is the variance $\sigma^{2}$ the formula for which is

$$
\sigma^{2}=\sum \frac{(x-\mu)^{2}}{N}
$$

The students are typically asked to memorize this formula because it is "so important. In Excel, there are functions to compute variances straight from the dataset. Most advanced calculators have built-in such functions. These are a perfect aid to analyze data, especially when the sets are large. 
But, in this paper, we are discussing the learning side of it. What exactly the variance is? What makes it large or small? How do outliers influence the variance of a dataset? Unfortunately, many the technology has made us and the students so lazy that we tend skip most of the underlying intuition.

We can start out by explaining that variance represents the variability of the data with respect to the center, that is mean. If the data is too scattered around the mean, the variance will be high. If all the numbers are close to the mean, the variance will be low. So, conceptually, we can add the distance of each point $(\mathrm{x})$ from the mean $(\mu)$ and divide this total by $\mathrm{N}$ to get the average distance. If it is high, the variability will be high, and vice-versa. But since the mean is the "center of gravity" - that is both halves of the mean are being equal weight, this total, and hence the average, will always be 0 . Our next option could be to use absolute values and we could call the resulting average as Mean Absolute Deviation.

However, we prefer to use the squared distance as this also exemplifies the "problematic" larger distances. So, we can measure the distance of each point (x) from the mean $\mu$, square it, and add them up. This will be give us the sum of the squared distances or deviations. The average of it can be called Mean Squared Deviation, popularly known as Variance. To emphasize one more time (to the student) - what is variance? It is the mean squared deviation (from the mean). A student who understands the variance this way will never forget the formula as he never has to memorize it. Now, while using a computer or a calculator to get variance, he will have a feel for what he is trying to accomplish. A larger than expected variance will create a red flag in his mind and prompt him to analyze data. All this because he understand what variance exactly represent. Another widely used book in Probability and Statistics by Keller [2] explains the use of Normal Distribution table in the following way:

"We standardize a random variable by subtracting its mean and dividing by its standard deviation. When the variable is normal, the transformed variable is called a standard normal random variable and denoted by $\mathrm{Z}$; that is,

$$
Z=\frac{x-\mu}{\sigma}
$$

Those of us who know statistics well can understand the above statement which seems quite "obvious". But how will a student who is already struggling see it?

Instead, we can start by explaining that we measure the distance of a point from the mean in terms of standard deviations because the standard deviation (variability) impacts the distribution. This distance is called z-score. So, if the mean is 60 and standard deviation is 20 , a point 90 will be $(90-60) / 20=1.5$ standard deviations away from the mean. This is what $\mathrm{z}$-score is. And, if the number is 30 , then the $\mathrm{z}$-score will be -1.5 indicating that we are at the same distance, but on the left side of the mean.

This explanation will also make the student understand, for example, t-score or F-score. He can also see why a high z-score will have a lower tail-area as high z-score implies a larger distance from the mean.

Because of the ease of availability of statistical functions on the computer, such as Norm. Dist in Excel, many of us completely skip the whole process of explaining the central idea behind such distribution because all we have to do is enter the relevant numbers such as $\mathrm{x}, \mu$, and $\sigma$ and we get the probability. The problem is, as we have seen in our classes, students trained this way can't explain what they get because they have no sense of what exactly they have done. 
International Journal on Integrating Technology in Education (IJITE) Vol.8, No.1, March 2019

\section{LINES AND CiRCLES}

What is the slope of a line that passes through $(3,5)$ and $(7,7)$ ? The formula for this will be

$$
\text { Slope }=\frac{\left(y_{2}-y_{1}\right)}{\left(x_{2}-x_{1}\right)}=\frac{7-5}{7-3}=.5
$$

If the student has memorized the formula, calculating the slope is a very easy process. But how many will remember this formula once the semester is over?

However, taught properly, calculating slope (or other related functions) can be a breeze that the student will never forget. Just one look at the image below will make the student never need the formula again.

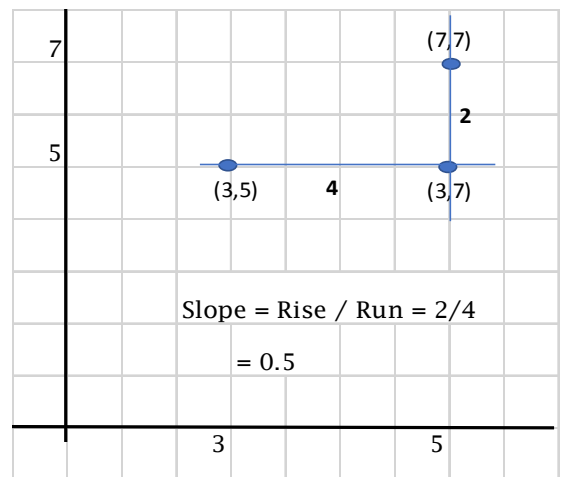

And, while we are at it, we can also talk about the distance between two points using Pythagoras theorem which says $c^{2}=a^{2}+b^{2}$. So the distance between $(3,5)$ and $(7,7)$ will be $\sqrt{2^{2}+4^{2}}=$ $\sqrt{20}$. The interesting point is, the distance formula itself can be derived now as shown below:

$$
\frac{\sqrt{(7-5)^{2}+(7-3)^{2}}}{\sqrt{\left(y_{2}-y_{1}\right)^{2}+\left(x_{2}-x_{1}\right)^{2}}}
$$

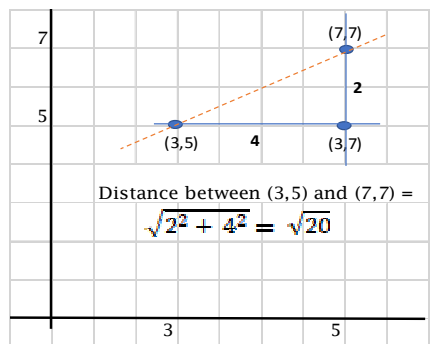

The same concept can be used to derive the equation of a circle. After all, a circle is nothing but a collection of points which are equidistant from a certain point - called the center. This distance is called the radius. So, if we have a point $(a, b)$, then a point $(x, y)$ which has a distance of $r$ from this point can be represented as

$$
\sqrt{(x-a)^{2}+(y-b)^{2}}=r
$$

Which is the equation of a circle. 
International Journal on Integrating Technology in Education (IJITE) Vol.8, No.1, March 2019

\section{CONCLUSiON}

By showing some very simple examples, we have tried to show that teaching and problem solving shouldn't be mixed. The process of teaching must involve understanding and common sense. Technology can be used in making the process easier as discussed in Sethi [3]. But using technology in bypassing the conceptual aspect of learning can be detrimental to the process. Once the students get the basic idea, then available tools can be used in solving the problems.

The new generation of students will swing more towards use of electronic devices such as calculators and computers, and concepts if not well explained in class as discussed in this paper will lead to overkill of computers and a plugin society. The lack of a clear understanding of the concepts will affect the student's ability to come up with a high level quick solution without a plug in formula. This type of ability is very much in demand in industries and consulting projects, where the participant in front of senior management has to quickly come up with the potential impact of say a change in forecast in a exponential smoothing model and how it will affect the outcome if we were to change the alpha value. The alpha value is only a percentage of the difference between actual and forecast and the participant can make the call quickly that considering a higher percentage of the variance can be a positive or negative impact based on historical data. This type of a holistic understanding is what we need to teach in classes as we explain the importance of "Why" we are learning a concept to how we can derive high level solutions with a simplistic understanding of the formulas. A deeper analysis can always follow to confirm the results and computers of course are very powerful to handle these tasks.

Modern electronic tools such as Excel, Tableau etc. are great ways for educators to create meaningful simulations to deep dive in classes [4]. The students, in turn can discover meaningful relationships, and develop new knowledge that was difficult to do in the past. The educators has to become the gate keepers in the education process to make sure that the technology becomes a aid in the learning process and not a plug in solution.

\section{REFERENCES}

[1] Stevenson, Operations Management, McGraw Hill Education, 2018, 13th edition, ISBN 978-1-25966747-3

[2] Keller, Gerald, Statistics for Management and Economics, Cengage Publishing, 10th Edition, ISBN10: 1285425456

[3] Sethi, Avanti, "Use of Excel in Statistics: Problem Solving vs Problem Understanding" International Journal on Integrating Technology in Education, Vol. 4, No. 4, December 2015

[4] Peck, Kyle L. and Dorricott, Denise, “Why Use Technology?”, 11-14, Vol. 51, April 1994.

[5] Carlson, Ben, "9 Things they don't teach you in business school”, Business Insider, October 2015.

[6] Rachael Law Schuetz, Gina Biancarosa \& Joanna Goode (2018) Is Technology the Answer? Investigating Students' Engagement in Math, Journal of Research on Technology in Education, 50:4, 318-332, DOI: 10.1080/15391523.2018.1490937

[7] Subhash C. Mehta PhD, Sanjay S. Mehta PhD \& Beh Lip Aun MBA (1999) The Evaluation of Business Text Books: An International Perspective, Journal of Professional Services Marketing, 19:2, 141-149, DOI: 10.1300/J090v19n02_09

[8] Jorge A. Gaytan \& John R. Slate (2002) Multimedia and the College of Business, Journal of Research on Technology in Education, 35:2, 186-205, DOI: 10.1080/15391523.2002.10782379 
International Journal on Integrating Technology in Education (IJITE) Vol.8, No.1, March 2019

\section{AUTHORS}

Dr. Avanti Sethi, a faculty member at Jindal School of Management at UT Dallas, received his MS and $\mathrm{Ph}$. D. in Operations Research from Carnegie-Mellon University in Pittsburgh, USA.

Dr. Ramesh Subramoniam, a faculty member at the Jindal School of Management at UT Dallas, received his PhD from Erasmus University, Rotterdam, NL and joined UT Dallas with 27 years of experience in industry and consulting.

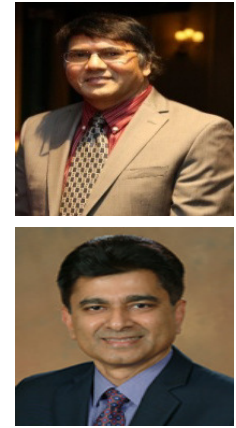

